\title{
Determinantes do Empreendedorismo Feminino no Brasil e Regiões
}

\author{
Samanda Silva da Rosa ${ }^{1}$ (D) | Vívian dos Santos Queiroz Orellana ${ }^{2}$ (D) | Gabrielito Rauter \\ Menezes $^{3}$ iD \\ ${ }^{1}$ Pontifícia Universidade Católica do Rio Grande do Sul. E-mail: samanda.srosa@gmail.com \\ ${ }^{2}$ Universidade Federal do Rio Grande. E-mail: viviansq13@gmail.com \\ ${ }^{3}$ Universidade Federal de Pelotas. E-mail: gabrielitorm@gmail.com
}

\begin{abstract}
RESUMO
O objetivo deste trabalho é verificar os determinantes do empreendedorismo feminino no Brasil e em suas cinco regiões usando os microdados da Pesquisa Nacional por Amostra de Domicílios (PNAD) do ano de 2015. O maior desafio relacionado a esse tema é compreender quais são os fatores que levam a mulher a se tornar empreendedora ou não. O procedimento de tomada de decisão individual considera diferentes fatores, sendo alguns destes sociais, demográficos e regionais. A estratégia empírica adotada foi um modelo probit para a estimação da escolha ocupacional. Os resultados sugerem que a probabilidade de a mulher empreender aumenta para a raça branca, idade, anos de estudos iniciais, chefe do domicílio, idade dos filhos, imigrante de retorno e com o aumento das horas dedicadas aos afazeres domésticos.
\end{abstract}

\section{PALAVRAS-CHAVE}

Empreendedorismo feminino, Probit, Brasil

\section{Determinants of Female Entrepreneurship in Brazil and Regions}

\section{ABSTRACT}

The objective of this essay is to verify the models of female entrepreneurship in Brazil and in its five regions based on models of occupational choice, using the microdata of the National Household Sample Survey (PNAD) of the year 2015. The greatest challenge related to this theme and is what is one of the factors that lead a woman to the option of becoming or not entrepreneurial. The individual decision-making procedure considers different factors, social, demographic and regional. The empirical strategy adopted was a probit model for estimating occupational choice. The results suggest that there are positive effects for a probability of the entrepreneurial woman as variables: race, age, years of initial studies, head of household, age of children, how to be a returning immigrant and hours dedicated to household chores.

\section{KEYWORDS}

Women entrepreneurship, Probit, Brazil

CLASSIFICAÇÃO JEL

L26, C25, J26 


\section{Introdução}

O propósito do presente trabalho é examinar os principais determinantes do empreendedorismo feminino no Brasil e nas cinco grandes regiões brasileiras. Para isso, utilizou-se um modelo de probabilidade com distribuição normal probit e dados da Pesquisa Nacional por Amostra de Domicílios (PNAD) de $2015^{1}$.

Segundo Wennekers e Thurik (1999) e Levent et al. (2003), foi dada maior atenção ao empreendedorismo devido à função que ele representa no desenvolvimento econômico, pois fomentar o empreendedorismo é incentivar o crescimento econômico, especialmente, pelo papel que ele desempenha de motivar a criação de empregos. A atividade empreendedora no Brasil tem se expandido a partir da década de 1990, devido à estabilidade da moeda e controle da inflação, com isso tem sido dada maior atenção sobre o assunto, por estar estreitamente correlacionado ao crescimento econômico.

O envolvimento das mulheres no empreendedorismo é um fenômeno mundial. No continente Europeu e nos Estados Unidos, a percentagem de mulheres empreendedoras é de $15 \%$ e 10,5\%, respectivamente OIT (1997). Conforme a pesquisa Global Entrepreneurship Monitor GEM (2016) de 2016, a mulher brasileira é uma das mais empreendedoras em comparação ao resto mundo, e detém o maior equilíbrio na relação entre homens e mulheres empreendedores no âmbito mundial. A percentagem de empreendedoras no Brasil é de 19,9\%, de acordo com PNAD de 2015 do Instituto Brasileiro de Geografia e Estatística (IBGE). A pesquisa GEM (2016) apontou que elas já são a maioria dos novos empreendedores do país, representando 51,5\%.

Várias pesquisas ${ }^{2}$ discutem os efeitos positivos do empreendedorismo sobre o crescimento e desenvolvimento econômico de países e regiões, através de aumento de postos de trabalho e arrecadação de tributos. Diante disso, o empreendedorismo é um assunto muito importante para economistas e policy-makers e vem ganhando força nos últimos anos, porque o Brasil se encontra em um momento de grandes mudanças no mercado de trabalho.

Os trabalhos empíricos sobre os determinantes do empreendedorismo nas economias desenvolvidas ${ }^{3}$ sugerem que tanto as características pessoais dos indivíduos quanto as características regionais influenciam nas decisões do indivíduo em se tornar um empreendedor. Nesse contexto, o desafio proposto a esse tema é compreender quais são os fatores determinantes que levam as mulheres a se tornarem empreendedoras no Brasil nas cinco grandes regiões. Dado que segundo a GEM (2016), existe uma diferença na taxa de empreendedorismo entre cada região brasileira, despertando o interesse de compreender como os aspectos regionais podem influenciar o empreendedorismo Neto et al. (2017).

O empreendedorismo é um processo que fomenta o desenvolvimento econômico de

\footnotetext{
${ }^{1}$ A escolha se deu em função de ser a base de dados mais atual na época do estudo.

${ }^{2}$ Ver Castanhar (2007); Barros e Pereira (2008); Sarfati (2013) Audretsch et al. (2015).

${ }^{3}$ Ver Armington e Acs (2002); Carree e Thurik (2008); Kangasharju (2000)
} 
um país, pois a criação de novos negócios auxilia, sobretudo, a geração de emprego e renda. Portanto, se faz necessário compreender a inserção da mulher no empreendedorismo também a nível regional, pois o Brasil é um país heterogêneo no âmbito dos seus indicadores econômicos, sociais e culturais. Essas diferenças regionais também são observadas na atividade empreendedora, e levar em consideração tais características, contribui para uma melhor compreensão do empreendedorismo feminino dentro do país.

As informações aqui apresentadas podem auxiliar no debate para a formulação de políticas públicas visando intensificar a participação feminina no empreendedorismo de forma mais clara, competitiva e economicamente sustentável, a nível de país e região. Uma vez que, no Brasil, este é o primeiro estudo que aborda o empreendedorismo feminino em nível nacional e regional a partir dos microdados da PNAD.

Com este propósito, este artigo foi estruturado em seis seções, incluindo esta introdução. Na Seção 2, apresenta-se o referencial teórico sobre a economia do empreendedorismo. Na Seção 3, é exposto a estratégia empírica adotada. Na Seção 4, os dados e tratamentos são apresentados. Na Seção 5, são descritos e discutidos os resultados e, por fim, as considerações finais do estudo na Seção 6.

\section{Referencial teórico e empírico}

O principal expoente sobre empreendedorismo, no contexto econômico, foi Schumpeter, o qual define empreendedor como sendo o agente apto a transformar uma ideia em uma inovação de sucesso em busca do lucro Schumpeter (1985). Tal concepção sobre o empreendedorismo na economia é considerado uma das contribuições econômicas mais relevantes do século passado Vieira (2015). Para Schumpeter (1985), o agente empreendedor aperfeiçoa a tecnologia disponível por meio da inovação dos meios de produção, fazendo uso de novas ideias, provocando assim um efeito em cascata e promovendo o desenvolvimento da economia como um todo ao longo do tempo. Ou seja, movendo a economia de um estado de repouso para um estado de expansão. Caracterizado pelo processo de destruição criativa, no qual o empreendedor introduz inovações, que superam os processos antigos e criam oportunidades Schumpeter (1985). Conforme Vieira (2015), se o agente econômico é hábil para propiciar todas estas mudanças, se faz necessário compreender o que o leva a buscar essas transformações.

De acordo com Fossen (2012) e Caliendo et al. (2014), o significado mais abrangente utilizado para definir o agente empreendedor é que todo o indivíduo que trabalha por conta própria é um empreendedor, seja ele empregador ou autônomo. Outros autores enfatizam o conceito de empreendedores em seus estudos Verheul et al. (2012); Bönte e Piegeler (2013). São definições que tem por objetivo identificar a aptidão dos agentes por serem empresários, independentemente da circunstância de seu emprego atual.

Os trabalhos empíricos sobre os determinantes do empreendedorismo, nas eco- 
nomias desenvolvidas, indicam que não somente as características individuais dos agentes influenciam na escolha ocupacional do indivíduo pelo empreendedorismo, mas também as características regionais, levando em conta o espaço onde o empreendedor mora e são um importante vetor para determinar a prosperidade econômica de dada região Faggio e Silva (2014). Como o objetivo dos agentes é maximizar a utilidade, o indivíduo compara o retorno econômico proveniente da atividade empreendedora em relação ao retorno do emprego assalariado Tamvada (2007).

De acordo com Lucas (1978), alguns indivíduos apresentam maior habilidade empreendedora em comparação aos demais, ou seja, os indivíduos se comportam de forma heterogênea no modelo. Ao fazer a escolha ocupacional, os indivíduos optam pela atividade que lhes dá a maior utilidade esperada. Ao modo que, indivíduos alocados acima de certa fronteira de capacidade, ou seja, mais talentosos arriscam-se como empreendedores em detrimento dos outros que permanecem como empregados.

Segundo De Wit (1993), é possivel elaborar pesquisas sobre empreendedores através da hipótese de que as indústrias produzem bens homogêneos, os quais apresentam uma determinada demanda, $X(p)$ que é estritamente decrescente em seu preço $p$. Logo, os indivíduos podem optar por suas escolhas ocupacionais, na forma de trabalho assalariado por uma remuneração em forma de salário $w$ ou de forma empreendedora como um empresário em troca de um determinado lucro $\pi$. Em que os indivíduos diferem apenas na sua habilidade empreendedora $\theta$ conforme o destacado por Lucas (1978).

Assim, a habilidade empreendedora $\theta \in[\underline{\theta} \bar{\theta}]$ entre os indivíduos é indicada por $H(\theta)$. Onde $\theta$ representa uma elevada habilidade empreendedora e $\underline{\theta}$ o caso contrário. Admitindo que o produto produzido pelos indivíduos seja homogêneo, e que a capacidade de empreender afetará somente a função de custo do trabalho assalariado. Considerando que a função custo $c(\theta, x)$ e a função custo marginal são estritamente decrescentes em $\bar{\theta}$. Conclui-se que, ao empreender o indivíduo maximiza seu lucro $(\pi)$, elegendo o nível adequado de produto $x$ :

$$
\operatorname{Max}_{x}[\pi \equiv p x-c(\theta, x)]
$$

De modo que, o nível de produção e os lucros dependerão diretamente de $\underline{\theta}$. Portanto, quanto maior é $\theta$ mais elevado são os lucros e o nível de produção $x(\theta, p)$. $\mathrm{O}$ indivíduo, portanto, optará pela escolha ocupacional de empreendedor se $\pi(\theta, x)$ for maior do que a opção de salário $w$, e o equilíbrio determinado quando:

$$
\pi=p x-c\left(\theta^{*}, x\right)=w
$$

A propensão do indivíduo de se tornar empreendedor é representada por $\theta^{*}$, que expressa o caráter indiferente entre ser empreendedor ou emprego assalariado. Por- 
tanto, $\theta^{*}$ expressa a capacidade empreendedora inicial para um dado nível de $w$, quando $\theta<\theta^{*}$ o a atividade assalariada é mais vantajosa para o indivíduo, o oposto ocorre quando $\theta>\theta^{*}$ onde a atividade empreendedora é mais vantajosa.

De acordo com Parker (2018), as características do indivíduo, tais como, a aversão ao risco, a sua bagagem adquirida de trabalhos anteriores, o nível de escolaridade, o capital humano, a idade, assim como aspectos específicos de personalidade, são características que podem influenciar a escolha ocupacional do indivíduo pelo empreendedorismo. Outro aspecto relevante está atrelado às características regionais, como incentivos através de políticas públicas para fomentar o estabelecimento de empreendimentos (através de subsídios ou transferências governamentais Blau (1987)), os índices de desemprego da região, se há oportunidades para pequenas empresas, são fatores que contribuem na escolha ocupacional como trabalhador assalariado ou empreendedor ( Ács e Audretsch (2011); Reynolds et al. (1994)). Em localidades com árias urbanas que apresentam alta diversidade nas atividades econômicas e índices mais elevados de crescimento econômicos a escolha por empreender é motivada por oportunidade Bosma e Sternberg (2014).

Segundo Glaeser et al. (2010), o espaço onde o indivíduo está inserido, influencia suas escolhas pela carreira empreendedora, a qual acaba induzindo a economia local. No entanto, a economia regional tem dado pouca relevância aos empreendedores. Neste contexto Menezes e Feijó (2015) e Neto et al. (2017), ressaltam a diferença entre o capital empreendedor entre as regiões do Brasil. Evidenciando a importância de levar em consideração o caráter regional nos condicionantes do empreendedorismo a nível brasileiro.

Alguns fatores pessoais são apontados pela literatura como motivação para o estabelecimento de empresas por mulheres e segundo Naser et al. (2012) são considerados positivos por favorecer o empreendedorismo e o próprio trabalho. De acordo com Naser et al. (2012), Zanakis et al. (2012), Vale et al. (2014), Neto et al. (2017) e Moraes et al. (2020), alguns desses fatores estão relacionados às dificuldades financeiras que impulsionam as mulheres a abrirem o próprio negócio visando a independência financeira.

As mulheres empreendedoras esperam acumular capital além do que seria possivel com o trabalho assalariado, como apontado por Hermans et al. (2012), ou para melhorar seu poder de compra destacado por Beyda e Casado (2011), Bonet Fernandez et al. (2014) e Machado et al. (2016). O desejo de desenvolver a capacidade pessoal e de ter reconhecimento com a gestão da própria empresa também são importantes motivos para empreender, mesmo que para a materialização de uma oportunidade de negócio seja necessário enfrentar maiores desafios (Bonet Fernandez et al. (2014); Zanakis et al. (2012); Morris et al. (2006)). Neste contexto, destacam principalmente as empresas familiares em que as herdeiras, frequentemente, não têm espaço suficiente no negócio familiar e estabelecem sua própria empresa Machado (2011). 
Outros autores, como Davies-Netzley (2013) Still e Timms (2000) e Machado et al. (2016), apontam que as mulheres se engajam no empreendedorismo porque buscam uma jornada de trabalho flexivel para conciliar o trabalho e a família, onde na maioria dos casos elas enfrentam dupla jornada de trabalho, dedicando várias horas por dia para os afazeres domésticos. Já Carter e Robb (2002) mencionam que a formação de uma empresa também pode acontecer devido à reinserção feminina no mercado de trabalho após um longo período de repouso ou de desemprego, particularmente para cuidar de filhos pequenos ou de pessoas idosas. De acordo com Machado et al. (2016), as principais motivações para a mulher empreender, são em virtude da insatisfação com os empregos anteriores e em detrimento de rendimentos melhores.

Entretanto, o empreendedorismo feminino tem alguns obstáculos, dentre eles: a falta de apoio familiar segundo Zanakis et al. (2012) e a dificuldade em conciliar o trabalho e a família, visto que, até mesmo as pequenas empresas requerem muitas horas de trabalho. De acordo com Winn (2005), o trabalho e a família se complementam mutuamente para os homens, mas indicam dificuldades para as mulheres devido à pressão familiar. De modo que, as mulheres enfrentam dificuldades ao empreender, especialmente para aquelas com crianças pequenas Mathew (2010). Porém, Rees e Shah (1986) destacam que o apoio da família exerce uma probabilidade positiva do individuo se tornar empreendedor. Logo, Greene et al. (2003) salientam que as mulheres têm escasso acesso à rede de negócios, menos contato com outras empresas e pouca informação sobre as empresas em comparação aos homens.

Ao empreender, as mulheres se deparam com outros obstáculos associados à preparação pessoal dos empreendedores. A falta de experiência em gestão e treinamento é, na verdade, uma dificuldade enfrentada por homens e mulheres empreendedores, particularmente um conhecimento escasso sobre os planos de negócios e leis específicas para a criação de empresas Zanakis et al. (2012). Além disso, o ambiente cada vez mais competitivos para os empreendedores urbanos que investem em start-ups sem o devido amparo gerencial, também é um obstáculo para manter a saúde dos empreendimentos Freire-Gibb e Nielsen (2014).

Mayr e Peri (2008) mostram que a possibilidade de migração e retorno ao país de origem têm efeitos positivos sobre a probabilidade de empreender, pois ao regressar à sua localidade de origem, o indivíduo absorveu experiência internacional incrementando seu capital humano. Em países de renda média, tais como: Europa Oriental, Ásia e América Latina há mais indivíduos dispostos a emigrar.

Fatores associados ao crédito como fonte de capital inicial para empreender estão entre as dificuldades para o estabelecimento de empresas (Mathew (2010); Winn (2005)). Para os autores Roper e Scott (2009), as mulheres têm mais dificuldade em obter crédito do que os homens. Estudos identificaram obstáculos no acesso ao crédito e taxas de lucros menores para as mulheres Greene et al. (2003).

Mulheres ainda enfrentam dificuldades em razão do viés de gênero, uma vez que 
as mulheres podem ser consideradas sensiveis, dóceis, fracas e sem a capacidade de trabalhar dentro de um ambiente empresarial (Gray e Finley-Hervey (2005); Welter e Smallbone (2008)). Ademais, Zanakis et al. (2012) destaca a importância da autoestima para as pessoas que desejam estabelecer seu próprio negócio. Shragg et al. (1992) afirmam que a diminuição da autoconsciência e baixa estima são verdadeiras barreiras para o estabelecimento do empreendedorismo pelas mulheres.

À semelhança do que ocorre no mercado de trabalho, o aspecto gênero vem recebendo muita atenção e inúmeros estudos passaram a identificar se as diferenças, nos rendimentos, entre homens e mulheres em relação ao trabalho assalariado também se reflete entre os empreendedores (Furdas e Kohn (2010); Grilo e Thurik (2006); Parker (2018)). Ser casada e ter filhos são características que aumentam, significativamente, a chance de as mulheres serem empreendedoras segundo Parker (2018). Embora essas características possam estar associadas no mercado de trabalho, o empreendedorismo permite uma flexibilidade na maneira de combinar trabalho com as atividades domésticas e do cuidar de filhos.

A partir deste propósito, Bernat et al. (2017) salienta em seu trabalho um conjunto de elementos associados a decisão do indivíduo em se tornar um empreendedor, bem como as características que evidenciam a diferença de gênero na atividade empresarial na América Latina. Para tanto, empregaram modelos logit, com a finalidade de estimar a atividade empresarial de acordo com três diferentes definições de empreendedorismo. Ademais, se estimou o hiato de gênero empregando a metodologia de decomposição de Fairlie's. Destacando que as diferenças nas características observáveis explicam entre 23 e $38 \%$ da disparidade total entre os gêneros.

Neto et al. (2017) abordaram em seu estudo as características socioeconômicas e geográficas que determinam o perfil do indivíduo empreendedor das cinco regiões brasileiras. Obteve-se como resultados que a educação exerce papéis opostos sobre a decisão empreendedora, uma vez que o acréscimo de anos de estudo favorece um aumento na probabilidade de um indivíduo se tornar empregador, bem como reduz a probabilidade do indivíduo ser um autônomo. Esses resultados divergem do observado por Rees e Shah (1986) e Taylor (1996), em que a educação apresenta efeitos positivos sobre a escolha de um indivíduo se tornar empreendedor.

E como regra, as mulheres iniciam com pequenas empresas e com poucos funcionários Morris et al. (2006). De acordo com a GEM (2016) as mulheres empreendem principalmente no setor de serviços, tais como, restaurantes e outros estabelecimentos de serviços de alimentação e bebidas, cabeleireiras e atividades de tratamento de beleza, comércio varejista de artigos de vestuário e acessórios e serviços domésticos.

Segundo Silva (2017), o empreendedorismo feminino é um instrumento eficaz na geração de renda, principalmente em momentos de crise econômica. E como alternativa às mulheres que, de maneira geral, acumulam múltiplas tarefas, não apenas com atividades relacionadas ao trabalho, mas também com afazeres domésticos e cui- 
dados com a família. Em sua pesquisa para o Brasil, observou efeitos significativos positivos para escolaridade e ser casada.

De acordo com Oliveira (2018) a decisão pelo empreendedorismo feminino no Brasil, está diretamente relacionada com as escolhas primárias das mulheres, tais como, investir ou não em capital humano, por meio de anos de estudos, casar-se, a fertilidade e as ambições no trabalho. Nos últimos vinte anos, as mulheres estão se inserindo no empreendedorismo cada vez mais jovens, ou seja, estão mais propensas ao trabalho por conta própria, permitindo que as mulheres ocupem carreiras que em outros momentos foram majoritariamente masculinas.

Enfim, a breve revisão de literatura apresentada destacou fatores determinantes sobre a escolha ocupacional da mulher pelo empreendedorismo. Porém, estudos para o Brasil, específicos para mulheres, ainda são escassos, e pela ótica regional são inexistentes.

\section{Estratégia empírica}

O modelo utilizado é um probit para estudar a probabilidade de ser empreendedor e permite estudar o empreendedorismo como escolha ocupacional, comparando com outra ocupação, a assalariada.

Suponha que as mulheres se deparem $\operatorname{com} j=1, \ldots, s$ alternativas de ocupações: empreendedora, representada por $E$, e outra atividade remunerada assalariada, denominada por $A$. Cada mulher apresenta um vetor $X$, que indica suas características observáveis, e uma função de utilidade ao escolher determinada ocupação $j \in s$, que é expressa por $U j=U(X ; j)+u_{j}$. A variável latente $Z^{*}$ expressa o benefício que uma mulher $i$ tem ao escolher a ocupação $E$ em relação à ocupação $P$ :

$$
Z^{*}=U(X ; E)-U(X ; P)+u_{E}-u_{P}
$$

De acordo com Parker (2004) Parker (2018), $U(. ;$.) é linear e pode ser operado na forma $U(X ; j)=\beta_{j}^{\prime} X$, sendo $\beta_{j}$ os vetores de parâmetros e $u_{j}$ a utilidade não observada. A Equação 3 mostra que o indivíduo irá preferir ser empreendedor ao invés de trabalhador assalariado quando a variável latente for $Z^{*} \geq 0$, que é representada por uma variável binária $Z$ da seguinte forma:

$$
Z^{*}=\beta^{\prime} X+\epsilon, Z=\left\{\begin{array}{l}
1 \text { se } Z^{*}>0 \\
0 \text { se } Z^{*}=0
\end{array}\right.
$$

onde, $\left(\beta_{E}^{\prime}-\beta_{P}^{\prime}\right) X=\beta^{\prime} X$ e $u_{E}-u_{P}=\epsilon$; $\epsilon$ é o termo de erro aleatório. Logo, $Z$ assume valor 1 se a mulher escolher ser empreendedora $\left(Z^{*}>0\right)$ e zero caso escolha ser trabalhadora remunerada $\left(Z^{*}=0\right)$. 
Para estimar a equação 4, é usado o modelo probit que admite que a distribuição do termo de erro obedeça a uma distribuição normal $\operatorname{Pr}(Z=1)=\Phi\left(\frac{\beta^{\prime} X}{\sigma}\right)$ e $\operatorname{Pr}(Z=0)=$ $1-\Phi\left(\frac{\beta^{\prime} X}{\sigma}\right)$, onde $\Phi($.$) indica a função de distribuição cumulativa da distribuição$ normal padrão. A equação de máxima verossimilhança, usada para estimar o modelo probit possui a forma a seguir:

$$
\ln L=\sum_{j \in S} p_{j} \ln \Phi\left(\beta^{\prime} X_{j}\right)+\sum_{j \notin S} p_{j} \ln \left\{1-\Phi\left(\beta^{\prime} X_{j}\right)\right\}
$$

onde, $p_{j}$ representa os pesos opcionais.

Para promover uma análise e interpretação dos coeficientes estimados, serão utilizados os efeitos marginais médios. A estimação por máxima verossimilhança dos coeficientes não permite uma interpretação direta dos resultados, apenas o sinal pode ser analisado. Deste modo, o efeito marginal é expresso por:

$$
\frac{\partial E(Z \mid X)}{\partial x}=\phi\left(\beta^{\prime} X\right) \beta^{\prime}
$$

Logo, $\beta^{\prime} X$ é definido como o vetor de coeficientes multiplicados por um vetor que possui valores para as variáveis dependentes. Portanto, o efeito marginal pode ser interpretado como a mudança na probabilidade para uma mudança infinitesimal em cada variável independente para as variáveis contínuas e a mudança discreta na probabilidade para variáveis dummies.

\section{Base de dados e tratamentos}

A base de dados utilizada é a PNAD de 2015, fornecida pelo Instituto Brasileiro de Geografia e Estatística (IBGE), sendo a última disponível no período da pesquisa. A amostra consta de mulheres com idade entre 18 e 64 anos. Esse recorte se baseia na GEM, que dispõe de critérios de análise usualmente utilizados na literatura para fins de estudo sobre o empreendedorismo. Conforme a metodologia da GEM (2016), o corte por idade é necessário para excluir indivíduos que não têm condições de estar inseridos no mercado de trabalho.

Outros recortes também foram feitos, como a exclusão de mulheres ocupadas com rendimento maior que $\mathrm{R} \$ 40.000,00^{4}$. O recorte nos rendimentos é necessário a fim de eliminar possíveis distorções na análise. Neste trabalho, considera-se empreendedoras as mulheres ocupadas como empregadoras e autônomas. A variável dependente $Y$ "empreendedora" assume o valor 1 se a mulher estiver ocupada em uma dessas ocupações e assume o valor zero se a mulher estiver inserida no mercado de trabalho

\footnotetext{
${ }^{4}$ Somente 6 observações estavam acima deste valor, as mesmas foram excluídas, pois se tratava de outliers.
} 
como assalariada.

As variáveis explicativas que captam as características socioeconômicas e demográficas utilizadas, para explicar a variável dependente " $Y$ ", foram selecionadas com base na teoria sobre empreendedorismo. Portanto, as covariadas utilizadas são: raça, idade, idade ao quadrado, dummies para escolaridade ${ }^{5}$, vive com cônjuge, chefe de família, horas dedicadas aos afazeres domésticos, renda do não trabalho, idade dos filhos ${ }^{6}$, migrante de retorno, região urbana, área metropolitana e, por fim, dummies para as regiões.

A partir da Tabela 1 constam as estatísticas descritivas da amostra após os recortes e exclusão dos valores missings. A amostra total é de 44.054 mulheres, em que 12.959 são empreendedoras e 31.095 assalariadas em todo Brasil.

A idade média da mulher empreendedora é de aproximadamente 42 anos. Enquanto a idade média da mulher assalariada é de aproximadamente 35 anos. A renda média do não trabalho das empreendedoras é de $\mathrm{R} \$ 187,78$ mensais e das assalariadas é de $\mathrm{R} \$ 434,17$ mensais.

Em relação à escolaridade, no que diz respeito à escolaridade entre nove e onze anos de estudo, as mulheres empreendedoras representam 38\% e as assalariadas 4,68\%. Para níveis de escolaridade mais elevados, com doze anos ou mais de estudo, as mulheres que empreendem representam 19\% e as mulheres assalariadas, aproximadamente $25 \%$ da amostra. A região Sudeste é a que se destaca com a maior parcela de mulheres assalariadas com aproximadamente 35\%. Enquanto, a região Nordeste é a que se destaca com a maior parcela de mulheres empreendedoras com aproximadamente $30 \%$.

A Tabela 2 mostra a distribuição regional das mulheres pelas ocupações empregadoras, assalariadas e empreendedoras (empregadoras mais assalariadas). As mulheres que estão ocupadas em trabalho assalariado são 31.095 da amostra, à medida que 12.959 são mulheres com atividade empreendedora.

Nota-se, a partir dos dados da Tabela 2, que das 12.959 empreendedoras presentes na amostra utilizada, $28 \%$ encontram-se no Sudeste, $30 \%$ no Nordeste, $15 \%$ no Sul, $15 \%$ no Norte e $12 \%$ no Centro-Oeste do país. Com relação às assalariadas são 31.095 indivíduos, dos quais 35\% estão no Sudeste, 23\% no Nordeste, $20 \%$ no Sul, $11 \%$ na região Norte e $11 \%$ no Centro-Oeste do país. Além disso, pode-se notar que a razão entre empreendedoras e assalariadas é maior no Norte do Brasil com relação às demais regiões. Em contraponto a isso, se tem que a razão entre empregadores e autônomos é menor nas regiões Sudeste e Sul em comparação com as demais regiões.

Com base nas informações obtidas a partir do banco de dados da PNAD (2015), na

\footnotetext{
${ }^{5}$ A escolaridade está classificada da seguinte forma: sem instrução, 1-4 anos de estudo, 5-8 anos de estudo, 9-11 anos de estudo e 12 anos de estudo ou mais.

${ }^{6}$ A idade dos filhos está classificada como: até 1 ano de idade, $>1-5$ anos de idade, $>5-10$ anos de idade.
} 
Tabela 1. Estatística descritiva da amostra.

\begin{tabular}{|c|c|c|c|c|}
\hline \multirow[b]{2}{*}{ Atributos Pessoais } & \multicolumn{2}{|c|}{ Empreendedora } & \multicolumn{2}{|c|}{ Assalariada } \\
\hline & Média & Desvio-Padrão & Média & Desvio-Padrão \\
\hline Branco & 0,4414 & 0,4965 & 0,4850 & 0,4997 \\
\hline Idade & 42,2465 & 11,2908 & 34,7787 & 10,8364 \\
\hline Idade $^{2}$ & 1912,244 & 954,9992 & 1326,987 & 820,3112 \\
\hline \multicolumn{5}{|l|}{ Anos de Estudo } \\
\hline Sem instrução & 0,0453 & 0,2081 & 0,0165 & 0,1275 \\
\hline 1 a 4 anos & 0,1230 & 0,3284 & 0,0463 & 0,2102 \\
\hline 5 a 8 anos & 0,2218 & 0,4155 & 0,1345 & 0,3412 \\
\hline 9 a 11 anos & 0,3843 & 0,4864 & 0,0468 & 0,4989 \\
\hline 12 anos ou mais & 0,1946 & 0,3959 & 0,2825 & 0,4502 \\
\hline \multicolumn{5}{|l|}{ Familia } \\
\hline Vive com cônjuge & 0,6656 & 0,4717 & 0,5259 & 0,4993 \\
\hline Chefe da família & 0,4330 & 0,4955 & 0,3360 & 0,4723 \\
\hline Afazeres domésticos (horas) & 21,4339 & 14,5656 & 15,8669 & 12,0718 \\
\hline \multicolumn{5}{|l|}{ Idade das crianças } \\
\hline Até 1 ano & 0,0358 & 0,1869 & 0,0338 & 0,1851 \\
\hline$>1-5$ anos & 0,5754 & 1,5393 & 0,5311 & 1,4330 \\
\hline$>5-10$ anos & 1,8266 & 4,0267 & 1,6549 & 3,7979 \\
\hline \multicolumn{5}{|l|}{ Renda } \\
\hline Renda de não trabalho & 187,7799 & 793,8971 & 77,7100 & 434,1749 \\
\hline \multicolumn{5}{|l|}{ Variáveis Demográficas } \\
\hline Migrante de retorno & 0,0446 & 0,2064 & 0,0275 & 0,1638 \\
\hline Urbano & 0,8832 & 0,3211 & 0,9476 & 0,2226 \\
\hline Metrópole & 0,4001 & 0,4899 & 0,4577 & 0,4982 \\
\hline Norte & 0,1510 & 0,3581 & 0,1076 & 0,3098 \\
\hline Nordeste & 0,3047 & 0,4603 & 0,2322 & 0,4222 \\
\hline Sul & 0,1552 & 0,3621 & 0,1970 & 0,3977 \\
\hline Centro-oeste & 0,1064 & 0,3083 & 0,1130 & 0,3166 \\
\hline Sudeste & 0,2825 & 0,4502 & 0,3500 & 0,4769 \\
\hline Observações & & 12.959 & & 31.095 \\
\hline
\end{tabular}

Fonte: Elaboração própria.

região Sudeste, $25 \%$ das mulheres economicamente ativas são consideradas empreendedoras. Assumindo como empreendedoras o conjunto de empregadoras e autônomas, no Sul 24\% são empreendedoras, no Norte 37\%, no Nordeste 35\% e no CentroOeste 28\%. Para o Brasil, 29\% das mulheres são empreendedoras. 
Tabela 2. Distribuição das mulheres nas regiões brasileiras.

\begin{tabular}{lcccccc}
\hline \hline \multicolumn{1}{c}{ Região } & N $^{\circ}$ obs. & Empreend.** & Autônoma & Empregadora & $\begin{array}{c}\text { Assalariada } \\
\text { Empreend. } \\
\text { por Região }\end{array}$ \\
\hline Sudeste & 14.546 & 3.661 & 3.158 & 503 & 10.885 & 0,28 \\
Sul & 8.140 & 2.012 & 1.669 & 343 & 6.128 & 0,30 \\
Norte & 5.304 & 1.958 & 1.797 & 161 & 3.346 & 0,15 \\
Nordeste & 11.171 & 3.949 & 3.626 & 323 & 7.222 & 0,15 \\
Centro-Oeste & 4.893 & 1.379 & 1.172 & 207 & 3.514 & 0,12 \\
Total & $\mathbf{4 4 . 0 5 4}$ & $\mathbf{1 2 . 9 5 9}$ & $\mathbf{1 1 . 4 2 2}$ & $\mathbf{1 5 3 7}$ & $\mathbf{3 1 . 0 9 5}$ & $\mathbf{1 , 0}$ \\
\hline
\end{tabular}

Fonte: Elaboração própria.

*Porcentagem de empreendedoras por região.

${ }^{* *}$ Representa o somatório das Autônomas (4 $4^{\underline{a}}$ coluna) e Empregadoras (5 $5^{\underline{a}}$ coluna).

\section{Resultados}

A Tabela 3 apresenta o efeito marginal da probabilidade de as mulheres se tornarem empreendedoras no Brasil. Também foi estimado o modelo probit para cada região do país e os resultados dos efeitos marginais são apresentados na Tabela 3. O Brasil é um país de grande dimensão territorial, com características muito heterogêneas entre suas regiões. Assim, é importante entender as diferenças regionais através dos principais fatores determinantes do empreendedorismo feminino.

O resultado do teste de Wald indica que as variáveis explicativas são conjuntamente importantes para explicar a variável dependente. A classificação preditiva aponta que o modelo prevê corretamente 74,03\% dos eventos para o Brasil. Em nível regional, o teste de Wald apontou que foram previstas corretamente $75,95 \%$ dos eventos na região Sudeste, 76,89\% no Sul, 71,76\% no Norte, 72,44\% no Nordeste e, finalmente, 74,04\% no Centro-Oeste. Ainda é importante destacar que, em geral, os sinais dos coeficientes corresponderam ao esperado e as variáveis são estatisticamente significativas a 1\%, com exceção da variável idade ao quadrado que não apresenta resultado estatisticamente significativo.

O resultado da Tabela 3 permite inferir que a mulher de cor branca possui 1,6\% de probabilidade de ser empreendedora no Brasil, quando comparada com as demais raças. Em relação à raça no aspecto regional, as mulheres de cor branca das regiões Sul, Centro-Oeste e Sudeste apresentam, nesta ordem, 4,86\%, 2,71\% e 1,56\%, maior probabilidade de se tornarem empreendedoras, em comparação às demais raças (categoria omitida). Na região Nordeste, esse resultado aponta para uma redução de 2,51\% na probabilidade de a mulher de raça branca empreender. Esse resultado está de acordo com estudos realizados por Borjas e Bronars (1989) e Clark e Drinkwater (1998) em que mulheres de cor branca, no geral, apresentam mais chances de empreender em relação às demais raças. Outro aspecto importante, é o de que na região nordeste, de acordo com os dados da PNAD de 2015, um percentual de 64,9\% da 
Tabela 3. Efeito marginal do probit para Brasil e regiões.

\begin{tabular}{|c|c|c|c|c|c|c|}
\hline Variáveis & Brasil & Sudeste & Sul & Norte & Nordeste & Centro-Oeste \\
\hline \multirow[t]{2}{*}{ Branco } & $0.016^{* * *}$ & $0.0156^{* *}$ & $0.0486^{* * *}$ & -0.0091 & $-0.0251^{* * *}$ & $0.0271^{*}$ \\
\hline & $(0.0044)$ & $(0.0070)$ & $(0.0119)$ & $(0.0144)$ & $(0.0092)$ & (0.0139) \\
\hline \multirow[t]{2}{*}{ Idade } & $0.0069^{* * *}$ & $0.0050^{* * *}$ & $0.0081^{* * *}$ & 0.0055 & 0.0040 & $0.0139^{* * *}$ \\
\hline & $(0.0012)$ & $(0.0021)$ & $(0.0028)$ & $(0.0038)$ & $(0.0025)$ & $(0.0037)$ \\
\hline \multirow[t]{2}{*}{ Idade $^{2}$} & -0.0000 & -0.0000 & -0.0000 & 0.0000 & $-0.0000^{*}$ & -0.0000 \\
\hline & $(0.0000)$ & $(0.0000)$ & $(0.0000)$ & $(0.0001)$ & $(0.0000)$ & $(0.0000)$ \\
\hline \multicolumn{7}{|l|}{ Anos de Estudo } \\
\hline \multirow{2}{*}{1 a 4 anos } & $0.0551^{* * *}$ & 0.0361 & -0.0108 & $0.1013^{* * *}$ & $0.1118^{* * *}$ & 0.0150 \\
\hline & $(0.0102)$ & $(0.0190)$ & $(0.0237)$ & $(0.0300)$ & (0.0190) & $(0.0322)$ \\
\hline \multirow[t]{2}{*}{5 a 8 anos } & $0.0414^{* * *}$ & $0.0320^{*}$ & 0.0014 & $0.0818^{* * *}$ & $0.0876^{* * *}$ & 0.0210 \\
\hline & $(0.0087)$ & $(0.0161)$ & $(0.0201)$ & $(0.0257)$ & $(0.0142)$ & $(0.0264)$ \\
\hline \multirow[t]{2}{*}{9 a 11 anos } & $-0.0228^{* * *}$ & 0.0030 & -0.0202 & $-0.0495^{*}$ & $-0.0360^{* *}$ & -0.0186 \\
\hline & $(0.0080)$ & $(0.0147)$ & $(0.0188)$ & $(0.0231)$ & $(0.0148)$ & $(0.0237)$ \\
\hline \multirow[t]{2}{*}{12 anos ou mais } & $-0.0399^{* * *}$ & 0.0055 & $0.0479^{* *}$ & $-0.1439^{* * *}$ & $-0.1362^{* * *}$ & -0.0360 \\
\hline & $(0.0085)$ & $(0.0155)$ & $(0.0195)$ & $(0.0255)$ & $(0.0166)$ & $(0.0249)$ \\
\hline \multirow[t]{2}{*}{ Migrante de retorno } & $0.0433^{* * *}$ & 0.0380 & 0.0269 & 0.0402 & $0.0691^{* * *}$ & 0.0251 \\
\hline & $(0.0107)$ & $(0.0201)$ & $(0.0227)$ & $(0.0362)$ & $(0.0205)$ & $(0.0304)$ \\
\hline \multirow[t]{2}{*}{ Vive com cônjuge } & $0.0737^{* * *}$ & $0.0674^{* * *}$ & $0.0463^{* * *}$ & $0.0812^{* * *}$ & $0.0860^{* * *}$ & $0.0891^{* * *}$ \\
\hline & $(0.0046)$ & $(0.0079)$ & $(0.0111)$ & $(0.0133)$ & $(0.0090)$ & $(0.0140)$ \\
\hline \multirow[t]{2}{*}{ Chefe da família } & $0.0352^{* * *}$ & $0.0342^{* * *}$ & $0.0233^{* *}$ & $0.0463^{* * *}$ & $0.0307^{* * *}$ & 0.0256 \\
\hline & $(0.0045)$ & $(0.0078)$ & $(0.0104)$ & $(0.0133)$ & $(0.0090)$ & $(0.0136)$ \\
\hline \multirow[t]{2}{*}{ Horas de afazeres dom. } & $0.0031^{* * *}$ & $0.0030^{* * *}$ & $0.0025^{* * *}$ & $0.0046^{* * *}$ & $0.0032^{* * *}$ & $0.0021^{* * *}$ \\
\hline & $(0.0001)$ & $(0.0002)$ & $(0.0111)$ & $(0.0004)$ & $(0.0002)$ & $(0.0004)$ \\
\hline \multicolumn{7}{|l|}{ Idade das Crianças } \\
\hline \multirow[t]{2}{*}{ Até 1 ano } & $0.0390^{* * *}$ & $0.0415^{* *}$ & 0.0056 & 0.0340 & $0.0664^{* * *}$ & 0.0173 \\
\hline & $(0.0105)$ & $(0.0194)$ & $(0.0258)$ & $(0.0262)$ & $(0.0211)$ & $(0.0310)$ \\
\hline \multirow[t]{2}{*}{$>1-5$ anos } & $0.0098^{* * *}$ & $0.0101^{* * *}$ & $0.0114^{* * *}$ & $0.0122^{* * *}$ & 0.0041 & $0.0144^{* * *}$ \\
\hline & $(0.0013)$ & $(0.0024)$ & $(0.0032)$ & $(0.0034)$ & $(0.0028)$ & $(0.0041)$ \\
\hline \multirow[t]{2}{*}{$>5-10$ anos } & $0.0015^{* * *}$ & 0.0013 & $0.0036^{* * *}$ & 0.0001 & 0.0013 & 0.0012 \\
\hline & $(0.0005)$ & $(0.0009)$ & $(0.0012)$ & $(0.0013)$ & $(0.0010)$ & $(0.0015)$ \\
\hline \multirow[t]{2}{*}{ Renda do não trabalho } & $0.00003^{* * *}$ & $0.00002^{* * *}$ & 0.00001 & $0.00006^{* * *}$ & $0.0006^{* * *}$ & $0.00003^{* * *}$ \\
\hline & $(0.0000)$ & $(0.0000)$ & $(0.0000)$ & $(0.0000)$ & $(0.0000)$ & $(0.0000)$ \\
\hline \multirow[t]{2}{*}{ Urbano } & $-0.1050^{* * *}$ & -0.0229 & $-0.1305^{* * *}$ & $-0.1369^{* * *}$ & $-0.0968^{* * *}$ & -0.0242 \\
\hline & $(0.0075)$ & $(0.0188)$ & $(0.0159)$ & $(0.0188)$ & $(0.0129)$ & $(0.0281)$ \\
\hline \multirow[t]{2}{*}{ Metrópole } & $-0.0171^{* * *}$ & -0.0029 & $-0.0324^{* * *}$ & $0.0705^{* * *}$ & $-0.0542^{* * *}$ & $-0.0517^{* * *}$ \\
\hline & $(0.0042)$ & $(0.069)$ & $(0.0091)$ & $(0.0137)$ & $(0.0085)$ & $(0.0139)$ \\
\hline \multirow[t]{2}{*}{ Norte } & $0.0991^{* * *}$ & & & & & \\
\hline & $(0.0067)$ & & & & & \\
\hline \multirow[t]{2}{*}{ Nordeste } & $0.0812^{* * *}$ & & & & & \\
\hline & $(0.0053)$ & & & & & \\
\hline Sul & $-0.0225^{* * *}$ & & & & & \\
\hline & $(0.0061)$ & & & & & \\
\hline Centro-Oeste & $0.0339^{* * * *}$ & & & & & \\
\hline & $(0.0071)$ & & & & & \\
\hline Observações & 44,054 & 14,546 & 8,140 & 5,304 & 11,171 & 4,893 \\
\hline Log-Verossimilhança & $-23412,131$ & $-7473,474$ & $-4033,79$ & $-2969,620$ & $-6057,814$ & $-2569,511$ \\
\hline Teste de Wald & 5740,22 & 1369,25 & 917,53 & 878,50 & 2025,74 & 595,18 \\
\hline Classificação preditiva & $74.03 \%$ & $75,95 \%$ & $76,89 \%$ & $71,76 \%$ & $72,44 \%$ & $74,04 \%$ \\
\hline
\end{tabular}

Fonte: Elaboração própria.

Nota: os desvios-padrões são robustos à heterocedasticidade.

"Parâmetros significativos a $10 \%$.

** Parâmetros significativos a 5\%.

**** Parâmetros significativos a $1 \%$. 
população era composto por pessoas pardas, o que corrobora com a probabilidade de que menos mulheres brancas empreendam nessa região.

A idade, por sua vez, é utilizada como uma proxy para experiência no mercado de trabalho e mostra que a probabilidade de empreender aumenta em aproximadamente 0,7\% a cada ano de idade da mulher no Brasil. Ainda considerando a variável idade, os resultados mostram que um ano a mais de idade aumenta a probabilidade de as mulheres se tornarem empreendedoras nas regiões sudeste, sul e centro-oeste em 0,50\%, 0,81\%, e 1,39\% respectivamente. Tal resultado está de acordo com o encontrado por Menezes e Feijó (2015) para homens e mulheres do Brasil usando a mesma metodologia. Em contrapartida, a idade ao quadrado apresenta um valor muito pequeno e sinal negativo na região Nordeste, o que significa que a chance de se tornar empreendedora aumenta, porém há taxas decrescentes com a idade. Os indivíduos são mais propensos a se tornarem empreendedores à medida que envelhecem, porém o empreendedorismo se torna menos atrativo em idade avançada devido a menor expectativa de vida, ou seja, há o risco de não haver tempo de vida suficiente para recuperar as perdas de investimentos feitos em um negócio Parker (2018).

Quanto aos anos de estudo, é possível observar que a probabilidade de a mulher ser empreendedora, no Brasil, se eleva nas primeiras faixas de escolaridade e se reduz para as mais escolarizadas. De um a quatro anos de estudo, a probabilidade é de $5,51 \%$ e cai para $4,14 \%$ quando a mulher possui de cinco a oito anos de estudo, em comparação a sem instrução (variável omitida). Para as mulheres que possuem doze anos de estudo ou mais, a probabilidade de se tornarem empreendedoras diminui significativamente em aproximadamente 4\%. Esse resultado está de acordo com o encontrado por Menezes e Feijó (2015), em que indivíduos com mais instrução apresentam maiores chances no mercado de trabalho assalariado. Ainda com relação à escolaridade, observa-se que as mulheres que possuem de 1 a 4 anos de estudo são mais propensas a se tornarem empreendedoras nas regiões Norte e Nordeste, $10,13 \%$ e 11,18\%, respectivamente, com relação às sem instrução. Já as mulheres com 5 a 8 anos de estudo têm mais probabilidade de empreender no Sudeste 3,2\% e, principalmente, no Norte $8,18 \%$ e Nordeste $8,76 \%$. Esses resultados corroboram os encontrados por Menezes e Feijó (2015) e Neto et al. (2017) uma vez que as mulheres apresentam um nivel de capital humano insuficiente para ingressar em carreiras bem remuneradas, porém, o suficiente para ingressar no mercado de trabalho como empreendedoras por necessidade.

Para as mulheres mais instruídas, se nota que há uma menor probabilidade ao empreendedorismo no Norte e Nordeste, respectivamente: 4,95\% e 3,60\%, para o ensino médio, e 14,39\% e 13,63\%, nível superior. Entretanto, as mulheres com ensino superior residentes da região Sul possuem maior probabilidade de se tornarem empreendedoras, 4,79\%. Esse resultado reflete a disparidade educacional existente por raça na região Nordeste, uma vez que, em torno de 69\% das pessoas brancas têm o nível de instrução maior em comparação aos pretos e pardos Campante et al. 
(2004). Segundo Oliveira (2018), quanto maior o nível de instrução (capital humano) da mulher empreendedora, maiores serão seus rendimentos uma vez que, aumenta a produtividade a partir de melhores decisões gerenciais do próprio negócio. Blanchflower (2004) e Taylor (1996) destacam que a educação é um fator importante para se tornar empreendedor, contudo, quanto mais elevados são os níveis de estudo, mais propensos os indivíduos são aos trabalhos assalariados e isso acontece devido aos custos de oportunidade e para minimizar riscos envolvidos.

A posição que as mulheres ocupam dentro de suas famílias reflete na escolha ocupacional. Ser chefe de família, no Brasil, aumenta a probabilidade de a mulher se tornar uma empreendedora em 3,52\%, enquanto viver com o cônjuge eleva significativamente a probabilidade de ser empreendedora em 7,37\%. Esse resultado sugere que mulheres casadas são mais propensas ao empreendedorismo. Blanchflower (2004) e Parker (2004), Parker (2018) salientam que a relação significa mais segurança para a mulher assumir os riscos, pois dá o suporte emocional necessário e a renda do cônjuge oferece mais segurança mediante o risco do negócio.

Por seu turno, a variável chefe de família também exibe um efeito positivo sobre o empreendedorismo, sendo que o fato de viver conjugalmente eleva a probabilidade de a mulher ser empreendedora, destacando as regiões Norte 4,63\% e Sudeste 3,42\%. Lindh e Ohlsson (1996) destacam que a família ampara a mulher e funciona como alicerce para que o indivíduo assuma os riscos de ter um negócio próprio.

A posição que as mulheres ocupam na esfera familiar também afeta a escolha ocupacional. Por exemplo, viver com cônjuge aumenta a probabilidade de a mulher se tornar empreendedora em todas as regiões, principalmente no Centro-Oeste, Nordeste e Norte em 8,91\%, 8,60\% e 8,12\% respectivamente. Assim, as mulheres que têm uma união conjugal são mais propensas a serem empreendedoras, pois, conforme Rees e Shah (1986), o indivíduo que possui um parceiro estaria mais preparado para assumir riscos.

A idade dos filhos é de extrema importância na decisão de ocupação feminina, pois a probabilidade de uma mulher empreender com filhos de até um ano de idade é de 3,90\% no Brasil. No entanto, essa probabilidade diminui significativamente se a idade dos filhos aumenta mais do que um ano. A probabilidade de as mulheres se tornarem empreendedoras aumentam em $0,31 \%$ se elas dedicam mais horas em afazeres domésticos. Esses resultados sugerem que as mulheres recorrem a uma ocupação empreendedora para ter mais flexibilidade na jornada de trabalho e poder conciliar com os cuidados da casa e dos filhos pequenos. Uma maneira de conciliar os afazeres domésticos com a atividade laboral é exercer atividades empreendedoras na própria residência, ou seja, o empreendedorismo por necessidade. Na literatura empírica sobre empreendedorismo, não foi averiguado o impacto dessas variáveis na inserção feminina no empreendedorismo, portanto, esse estudo contribui com essa lacuna. 
No que se refere à idade dos filhos no aspecto regional, chama atenção que ter filho de até um ano de idade aumenta a probabilidade de ser empreendedora, principalmente nas regiões Sudeste e Nordeste, 4,15\% e 6,64\%, respectivamente. No entanto, ter filhos maiores não parece ser determinante para o empreendedorismo. Mulheres com crianças entre um ano de idade e cinco anos exibiram mais de $1 \%$ de propensão ao empreendedorismo nas regiões: Sudeste, Sul, Norte e Centro-Oeste. Já ser mãe de crianças com idade entre cinco e dez anos impacta positivamente a probabilidade da região Sul em 0,36\%. As horas dedicadas às atividades domésticas no domicílio também aumentam a probabilidade de a mulher ser empreendedora em todas as regiões brasileiras.

Em relação às mulheres que são migrantes de retorno, ou seja, que são naturais do estado de residência, porém já residiram em outra Unidade da Federação ou país estrangeiro, a probabilidade de empreender ao retornar ao seu estado de origem aumenta em 4,33\% no Brasil. Conforme Mayr e Peri (2008), no Brasil, a migração de retorno contribui positivamente para o empreendedorismo, pois aumenta o capital humano devido ao acúmulo de experiência em outras localidades e riqueza.

Com relação à variável de migração de retorno, a região Nordeste foi a única que apresentou significância estatística. Assim, a probabilidade de empreender depois de retornar para a região de origem aumenta no Nordeste em 6,91\%, sendo essa a região de onde mais emigram e retornam pessoas. A região Nordeste tem como característica histórica o deslocamento de pessoas para outras localidades, principalmente o Sudeste, em busca de oportunidades de trabalho. Porém, essa região também apresenta a maior parcela de remigrados do Brasil, aproximadamente $41 \%$ de todo o estoque de retornados do país entre os anos de 1995 e 2000 Gueiroz (2011). Em números absolutos, o montante de migrantes de retorno, na região Nordeste, entre 1997 e 2007 foi de 634 mil pessoas Ramalho e Silveira Neto (2009). Segundo Gueiroz (2011) chama atenção que a migração também favorece o incremento do capital humano e o acúmulo de riqueza que pode ser usada para abrir o próprio negócio na região de origem.

Com respeito ao local de residência, observa-se que mulheres que residem na área metropolitana ou na zona urbana apresentam probabilidade negativa em ser empreendedora no Brasil. Residir em zona urbana e em metrópoles diminui em 10,5\% e $1,71 \%$, respectivamente, a probabilidade de empreender. Tais resultados corroboram os achados de Menezes e Feijó (2015), mas divergem do estudo de Ács et al. (2008). Nas áreas urbanas e metropolitanas, há maior oferta de vagas de trabalho assalariado e salários mais elevados, o que pode favorecer a inserção feminina em ocupações assalariadas.

Residir em zona urbana reduz a probabilidade em 13,05\% e 13,69\% de ser empreendedora nas regiões Sul e Norte respectivamente. Segundo Ács et al. (2008), nas áreas urbanas há maior chance de a mulher conseguir um bom emprego assalariado. Além disso, residir em região metropolitana reduz a probabilidade de ser empreendedora, nas regiões Sul, Nordeste e Centro-Oeste em 3,24\%, 5,42\% e 5,17\%, respecti- 
vamente, com exceção da região Norte, onde a probabilidade é positiva em 7,05\%. A região Norte do Brasil apresenta características particulares, como a extração de cacau, açaí, castanha do Pará, e a pesca de peixes de água doce, nas proximidades das capitais. De modo que, o comércio desses produtos é realizado pelos próprios produtores, diretamente ao mercado consumidor, o que fomenta o empreendedorismo local. Estes resultados sugerem que em áreas metropolitanas, a decisão pelo trabalho assalariado pode ser beneficiada pelas condições de trabalho com remuneração mais elevada, ou seja, a utilidade do trabalho assalariado é mais vantajosa do que o risco de empreender. Krugman (1991) destaca a importância da geografia econômica explicação de resultados econômicos. Segundo Tamvada (2007) e Glaeser et al. (2010), a localização geográfica do indivíduo é um fator determinante na escolha entre o trabalho assalariado e o empreendedorismo.

As dummies de região visam captar os efeitos diferenciados das características locais sobre a probabilidade de as mulheres escolherem a ocupação empreendedora. As mulheres das regiões Norte e Nordeste têm maior probabilidade de se tornar empreendedora, 9,91\% e 8,12\%, respectivamente, em relação às da região Sudeste. A região Sul é a única que apresenta probabilidade negativa de 2,25\% de uma mulher residente nessa região vir a se tornar empreendedora. Tais resultados corroboram com Menezes e Feijó (2015), Neto et al. (2017) e Moraes et al. (2020), indicando a importância de consideram o elemento regional nos determinantes do empreendedorismo feminino.

\section{Considerações finais}

Esse trabalho teve como objetivo analisar quais os fatores determinantes do empreendedorismo feminino no Brasil e regiões a partir dos dados da PNAD de 2015. Entender o empreendedorismo regional ganha importância devido ao Brasil ser um país heterogêneo. Considerar as características regionais, proporciona uma melhor compreensão dos condicionantes do empreendedorismo feminino em função de existir uma desigualdade no capital empreendedor entre as grandes regiões brasileiras. Diferenças como, a qualificação das mulheres, o mercado de trabalho e rendimento médio das mulheres, podem desempenhar um papel fundamental na escolha ocupacional das mulheres.

Os resultados obtidos de escolha ocupacional apontam que existem efeitos significativos positivos para as seguintes variáveis: raça, idade, anos de estudos iniciais, assim como a idade dos filhos e viver com cônjuge. Já o fato de a mulher possuir mais anos de estudo, como o ensino médio e superior, apresenta um impacto negativo na escolha da mesma em se tornar empreendedora no Brasil.

Ademais, são observadas diferenças entre as regiões brasileiras, enquanto anos de estudos iniciais mostram que existem efeitos significativos positivos na probabilidade das mulheres das regiões Norte e Nordeste empreenderem. Esse resultado tem um forte indício de empreendedorismo por necessidade, sugerindo a necessidades de es- 
tudos mais aprofundados com foco no empreendedorismo feminino em cada estado dessas regiões. As escolaridades mais elevadas apresentam efeitos significativos negativos. O que pode indicar que, em regiões onde há menos postos de trabalho, mulheres com mais qualificação conseguem oportunidades vantajosas no mercado de trabalho assalariado não sendo interessante arriscar um empreendimento. Ou ainda, que nessas regiões as mulheres que arriscam empreender o fazem por oportunidade, com um grau de preparação maior no negócio. Correndo menos riscos, a partir de maior planejamento, as mulheres que vão empreender estão mais preparadas. A atividade empreendedora é de suma importância para o crescimento da economia nacional e regional, logo, políticas públicas que incentivem o empreendedorismo feminino devem ser desenvolvidas ainda na fase da educação básica, levando em conta as características de cada região. Ainda, se fazem necessárias mentorias, com foco na visão das oportunidades no mercado e, ainda, o planejamento inicial do negócio. Além de auxílio em crédito, pelas entidades financeiras, para que as mulheres possam abrir suas empresas.

Residir em região metropolitana apresenta efeitos significativos contrários entre as regiões. A região Nordeste é a única que apresenta efeitos significativos positivos em relação à probabilidade de a mulher empreender, os quais podem ser explicados por fatores como políticas governamentais, capacidade empreendedora e pesquisa e desenvolvimento. Com relação as regiões Sul, Nordeste e Centro-Oeste os efeitos significativos são negativos.

Por fim, este artigo contribuiu para a literatura sobre o tema ao produzir informações importantes sobre as mulheres empreendedoras no âmbito nacional e regional. Podendo colaborar com a criação de políticas públicas, principalmente, no que diz respeito à burocracia ao empreender e ainda a grande carga tributária. Visto que, estimular o empreendedorismo converge não só para maior autonomia financeira feminina, como também melhora seu bem-estar e estimula o desenvolvimento regional. Para trabalhos futuros, fica como sugestão desagregar o empreendedorismo regional em autônomo e empregador para entender se o empreendedorismo ocorre por oportunidade ou por necessidade.

\section{Referências}

Ács, Z. e Audretsch, D. (2011). Handbook of entrepreneurship research: An interdisciplinary survey and introduction $2^{\circ}$ ed. New York: Springer, volume 1. Springer Science \& Business Media.

Ács, Z. J., Bosma, N., e Sternberg, R. (2008). The entrepreneurial advantage of world cities: evidence from global entrepreneurship monitor data. Texto para discussão, Jena Economic Research Papers.

Armington, C. e Acs, Z. J. (2002). The determinants of regional variation in new firm formation. Regional studies, 36(1):33-45. 
Audretsch, D. B., Belitski, M., e Desai, S. (2015). Entrepreneurship and economic development in cities. The Annals of Regional Science, 55(1):33-60.

Barros, A. A. d. e Pereira, C. M. M. d. A. (2008). Empreendedorismo e crescimento econômico: uma análise empírica. Revista de administração contemporânea, 12(4):975-993.

Bernat, L. F., Lambardi, G., e Palacios, P. (2017). Determinants of the entrepreneurial gender gap in latin america. Small Business Economics, 48(3):727-752.

Beyda, T. T. e Casado, R. U. (2011). Relações de trabalho no mundo corporativo: possivel antecedente do empreendedorismo? Cadernos EBAPE. BR, 9(4):1066-1084.

Blanchflower, D. G. (2004). Self-employment: More may not be better. Texto para discussão, National Bureau of Economic Research.

Blau, D. M. (1987). A time-series analysis of self-employment in the united states. Journal of political economy, 95(3):445-467.

Bonet Fernandez, D., Scotto, M. J., e Fischer Colonimos, B. (2014). Entreprendre en france? les motivations des femmes. Texto para discussão, Department of Research, Ipag Business School.

Bönte, W. e Piegeler, M. (2013). Gender gap in latent and nascent entrepreneurship: driven by competitiveness. Small Business Economics, 41(4):961-987.

Borjas, G. J. e Bronars, S. G. (1989). Consumer discrimination and self-employment. Journal of political economy, 97(3):581-605.

Bosma, N. e Sternberg, R. (2014). Entrepreneurship as an urban event? empirical evidence from european cities. Regional studies, 48(6):1016-1033.

Caliendo, M., Fossen, F., e Kritikos, A. S. (2014). Personality characteristics and the decisions to become and stay self-employed. Small Business Economics, 42(4):787814.

Campante, F. R., Crespo, A. R., e Leite, P. G. (2004). Desigualdade salarial entre raças no mercado de trabalho urbano brasileiro: aspectos regionais. Revista Brasileira de Economia, 58(2):185-210.

Carree, M. A. e Thurik, A. R. (2008). The lag structure of the impact of business ownership on economic performance in oecd countries. Small business economics, 30(1):101-110.

Carter, N. M. e Robb, A. (2002). The role of risk orientation on financing expectations in new venture creation: Does sex matter. Frontiers of Entrepreneurship Research, 2002:170-181. 
Castanhar, J. C. (2007). Empreendorismo e desenvolvimento regional no Brasil. Uma análise da relação entre a criação de empresas e o desenvolvimento regional ao longo do tempo e de estratégias de empreendedores selecionados. Tese de Doutorado, Instituto Universitário de Lisboa, Lisboa - Portugal.

Clark, K. e Drinkwater, S. (1998). Ethnicity and self-employment in britain. Oxford Bulletin of Economics and Statistics, 60(3):383-407.

Davies-Netzley, S. A. (2013). Gendered capital: entrepreneurial women in American enterprise. Routledge.

De Wit, G. (1993). Determinants of Self-Employment (Heidelberg: Physica-Verlag). Springer.

Faggio, G. e Silva, O. (2014). Self-employment and entrepreneurship in urban and rural labour markets. Journal of Urban Economics, 84:67-85.

Fossen, F. M. (2012). Gender differences in entrepreneurial choice and risk aversion-a decomposition based on a microeconometric model. Applied Economics, 44(14):1795-1812.

Freire-Gibb, L. C. e Nielsen, K. (2014). Entrepreneurship within urban and rural areas: Creative people and social networks. Regional studies, 48(1):139-153.

Furdas, M. D. e Kohn, K. (2010). What's the difference?! gender, personality, and the propensity to start a business. IZA Discussion Paper N. 4778, available at SSRN.

GEM (2016). Global entrepreneurship monitor. Disponível em: http://www.gemconsortium.org/.

Glaeser, E. L., Rosenthal, S. S., e Strange, W. C. (2010). Urban economics and entrepreneurship. Journal of urban economics, 67(1):1-14.

Gray, K. R. e Finley-Hervey, J. (2005). Women and entrepreneurship in morocco: Debunking stereotypes and discerning strategies. The International Entrepreneurship and Management Journal, 1(2):203-217.

Greene, P. G., Hart, M. M., Gatewood, E. J., Brush, C. G., e Carter, N. M. (2003). Women entrepreneurs: Moving front and center: An overview of research and theory. Coleman White Paper Series, 3(1):1-47.

Grilo, I. e Thurik, A. R. (2006). Entrepreneurship in the old and new europe. In: Entrepreneurship, Growth, and Innovation, Página 75-103. Springer.

Hermans, J., Vanderstraeten, J., Dejardin, M., Ramdani, D., Stam, E., e van Witteloostuijn, A. (2012). Ambitious entrepreneurship: antecedents and consequences: Working papers. Faculty of Applied Economics.

Kangasharju, A. (2000). Regional variations in firm formation: Panel and crosssection data evidence from finland. Papers in Regional Science, 79(4):355-373. 
Krugman, P. (1991). Increasing returns and economic geography. Journal of political economy, 99(3):483-499.

Levent, T. B., Masurel, E., e Nijkamp, P. (2003). Diversity in entrepreneurship: ethnic and female roles in urban economic life. International journal of social economics, 30(11):1131-1161.

Lindh, T. e Ohlsson, H. (1996). Self-employment and windfall gains: evidence from the swedish lottery. The Economic Journal, 106(439): 1515-1526.

Lucas, R. E. (1978). On the size distribution of business firms. The Bell Journal of Economics, 9(2):508-523.

Machado, H. (2011). The challenge of female successors in a brazilian family business: a case study. D. Halkias, PW Thurman, C. Smith \& RS Nason. Father-Daughter Succession in Family Business A Cross-Cultural Perspective. Farnham: Gower Publishing Ltda.

Machado, H. P. V., Gazola, S., Fabricio, J. D. S., e Anez, M. E. M. (2016). Women entrepreneurs: Reasons and difficulties for starting in business. RAM. Revista de Administração Mackenzie, 17(3):15-38.

Mathew, V. (2010). Women entrepreneurship in middle east: Understanding barriers and use of ict for entrepreneurship development. International Entrepreneurship and Management Journal, 6(2):163-181.

Mayr, K. e Peri, G. (2008). Return migration as a channel of brain gain. Texto para discussão, National Bureau of Economic Research.

Menezes, G. R. e Feijó, F. T. (2015). Determinantes do empreendedorismo no brasil: uma análise da escolha ocupacional e dos rendimentos. XIII Encontro Nacional da Associação Brasileira de Estudos Regionais e Urbanos-XIII ENABER.

Moraes, I. S., de Camargo Neto, R. P., Orellana, V. S. Q., Menezes, G. R., et al. (2020). Entrepreneurship in brazil: A worthy endeavor? International Journal of Economics and Finance, 12(7):1-98.

Morris, M. H., Miyasaki, N. N., Watters, C. E., e Coombes, S. M. (2006). The dilemma of growth: Understanding venture size choices of women entrepreneurs. Journal of small business management, 44(2):221-244.

Naser, K., Nuseibeh, R., e Al-Hussaini, A. (2012). Personal and external factors effect on women entrepreneurs: Evidence from kuwait. Journal of Developmental Entrepreneurship (JDE), 17(02):1-23.

Neto, R. P. d. C., Barbosa, M. N., Orellana, V. d. S. Q., e Menezes, G. R. (2017). Condicionantes do empreendedorismo no brasil: uma análise regional. Revista Brasileira de Estudos Regionais e Urbanos, 11(4):447-466. 
OIT (1997). Organisation internationale du travail. programme des activités sectorielles. La promotion des femmes aux postes de direction. Genève: Bureau International du Travail.

Oliveira, V. R. (2018). Empreendorismo e desenvolvimento regional no Brasil. Uma análise da relação entre a criação de empresas e o desenvolvimento regional ao longo do tempo e de estratégias de empreendedores selecionados. Tese de Doutorado, Universidade Federal do Rio Grande do Sul, Porto Alegre, Brasil.

Parker, S. C. (2004). The economics of self-employment and entrepreneurship. Cambridge university press.

Parker, S. C. (2018). The economics of entrepreneurship. Cambridge University Press.

Queiroz, V. d. S. (2011). Migração de retorno, diferenciais de salários e autosseleção: evidências para o Brasil. Banco do Nordeste do Brasil.

Ramalho, H. e Silveira Neto, R. (2009). Migração de retorno e escolha ocupacional no brasil. Encontro Nacional da Associação Brasileira de Estudos Regionais e Urbanos, 7 .

Rees, H. e Shah, A. (1986). An empirical analysis of self-employment in the uk. Journal of applied econometrics, 1(1):95-108.

Reynolds, P., Storey, D. J., e Westhead, P. (1994). Cross-national comparisons of the variation in new firm formation rates. Regional studies, 28(4):443-456.

Roper, S. e Scott, J. M. (2009). Perceived financial barriers and the start-up decision: An econometric analysis of gender differences using gem data. International Small Business Journal, 27(2):149-171.

Sarfati, G. (2013). Estágios de desenvolvimento econômico e políticas públicas de empreendedorismo e de micro, pequenas e médias empresas (mpmes) em perspectiva comparada: os casos do brasil, do canadá, do chile, da irlanda e da itália. Revista de Administração Pública, 47(1):25-48.

Schumpeter, J. A. (1985). O fenômeno fundamental do desenvolvimento econômico. A teoria do desenvolvimento econômico. Rio de Janeiro: Nova Cultural.

Shragg, P., Yacuk, L., e Glass, A. (1992). Study of barriers facing albertan women in business. Journal of Small Business \& Entrepreneurship, 9(4):40-49.

Silva, M. S. d. (2017). Determinantes do empreendedorismo feminino no brasil: aplicação de um modelo de escolha ocupacional usando microdados da pnad de 2015. Dissertação de Mestrado, Pontifícia Universidade Católica do Rio Grande do Sul, Porto Alebre, BR.

Still, L. V. e Timms, W. (2000). Women's business: the flexible alternative workstyle for women. Women in management review, 15(5/6):272-283. 
Tamvada, J. P. (2007). Essays on entrepreneurship and economic development. Tese de Doutorado, Georg-August-Universität Göttingen, Göttingen, Germany.

Taylor, M. P. (1996). Earnings, independence or unemployment: why become selfemployed? Oxford Bulletin of Economics and Statistics, 58(2):253-266.

Vale, G. M. V., Corrêa, V. S., e Reis, R. F. d. (2014). Motivações para o empreendedorismo: necessidade versus oportunidade? Revista de Administração Contemporânea, 18(3):311-327.

Verheul, I., Thurik, R., Grilo, I., e Van der Zwan, P. (2012). Explaining preferences and actual involvement in self-employment: Gender and the entrepreneurial personality. Journal of economic psychology, 33(2):325-341.

Vieira, J. P. V. S. (2015). Religião e empreendedorismo no brasil: uma análise utilizando modelos de escolha ocupacional a partir do censo de 2010. Dissertação de Mestrado, Pontifícia Universidade Católica do Rio Grande do Sul, Porto Alebre, BR.

Welter, F. e Smallbone, D. (2008). Women's entrepreneurship from an institutional perspective: the case of uzbekistan. International Entrepreneurship and Management Journal, 4(4):505-520.

Wennekers, S. e Thurik, R. (1999). Linking entrepreneurship and economic growth. Small business economics, 13(1):27-56.

Winn, J. (2005). Women entrepreneurs: can we remove the barriers? The International Entrepreneurship and Management Journal, 1(3):381-397.

Zanakis, S. H., Renko, M., e Bullough, A. (2012). Nascent entrepreneurs and the transition to entrepreneurship: Why do people start new businesses? Journal of Developmental Entrepreneurship, 17(01):1250001.

(ल) Este artigo está licenciado com uma CC BY 4.0 license. 


\section{Apêndice}

\section{A. Tabela Suplementar}

Tabela A.1. Descrição das variáveis utilizadas nas regressões.

\begin{tabular}{|c|c|}
\hline Atributos pessoais & Definição \\
\hline Raça & Variável binária: 1 - branco; 0 - não branco. \\
\hline Idade & Idade em anos. \\
\hline Idade $^{2}$ & Idade ao quadrado. \\
\hline \multicolumn{2}{|l|}{ Anos de estudo } \\
\hline Sem instrução & Variável binária: 1 - indivíduos sem instrução; 0 para os demais. \\
\hline De 1 a 4 anos de estudo & Variável binária: 1 - possui de 1 a 4 anos de estudo; 0 - para os demais. \\
\hline De 5 a 8 anos de estudo & Variável binária: 1 - possui de 5 a 8 anos de estudo; 0 - para os demais. \\
\hline De 9 a 11 anos de estudo & Variável binária: 1 - possui de 9 a 11 anos de estudo; 0- para os demais. \\
\hline Acima de 12 anos de estudo & Variável binária: 1 - possui 12 ou mais anos de estudo; 0 - para os demais. \\
\hline \multicolumn{2}{|l|}{ Familia } \\
\hline Estado civil & Variável binária: 1 - vive com cônjuge; 0 - para os demais. \\
\hline Chefe & Variável binária: 1 - responsável pela família; 0 - para os demais. \\
\hline Afazeres domésticos (horas) & Horas dedicadas aos afazeres domésticos. \\
\hline \multicolumn{2}{|l|}{ Idade dos filhos } \\
\hline Até 1 ano & Variável binária: 1 - criança até 1 ano; 0 - para os demais. \\
\hline$>1-5$ anos & Variável binária: 1 - criança maior de 1 ano até 5 anos; 0 - para os demais. \\
\hline$>5-10$ anos & Variável binária: 1 - criança maior de 5 anos até 10 anos; 0 - para os demais. \\
\hline \multicolumn{2}{|l|}{ Renda } \\
\hline Renda de não trabalho & Variável binária: 1 - se recebe renda de não trabalho; 0 - se não recebe. \\
\hline \multicolumn{2}{|l|}{ Variáveis Demográficas } \\
\hline Migrante de retorno & Variável binária: 1 - se residiu em outro país ou estado; 0 - se não residiu. \\
\hline Urbano & Variável binária: 1 - se reside na região Urbana; 0 - se não reside. \\
\hline Agrícola & Variável binária: 1 - se reside na região Agrícola; 0 - se não reside. \\
\hline Metrópole & Variável binária: 1 - se reside na Metrópole; 0 - se não reside. \\
\hline Norte & Variável binária: 1 - se reside na região Norte; 0 - se não reside. \\
\hline Nordeste & Variável binária: 1 - se reside na região Nordeste; 0 - se não reside. \\
\hline Sul & Variável binária: 1 - se reside na região Sul; 0 - se não reside. \\
\hline Centro-oeste & Variável binária: 1 - se reside na região Centro-Oeste; 0 - se não reside. \\
\hline Sudeste & Variável binária: 1 - se reside na região Sudeste; 0 - se não reside. \\
\hline
\end{tabular}

Fonte: Elaboração própria. 